\title{
Tungsten isotopic constraints on heterogeneity of the NeoArchean Earth mantle
}

\author{
M. Chen', K. Suzuki and J. Kikuchi \\ 'SESS, Peking Univ., Beijing, China, 100871 \\ (mimi.chen@pku.edu.cn) \\ IFREE, JAMSTEC, Yokosuka, Japan, 237-0061
}

The short-lived ${ }^{182} \mathrm{Hf}^{182} \mathrm{~W}$ isotope system has been a uniquely useful tool in tracing the nature and evolution of the terrestrial geochemical reservoirs. However, its use has been hindered by the relative scarcity of $\mathrm{W}$ isotopic measurements on the samples closely linked to the early terrestrial mantle. Furthermore, questions on the mantle convection and mixing efficiency since late accretion remain to be fully answered.

To address these issues, high precision ${ }^{182} \mathrm{~W}$ isotope data were collected by MC-ICP-MS for the first time for the komatiites from the $\sim 2.78-2.65$ Ga Taishan Greenstone Belt, China. These samples overall show non-positive $\mu^{182} \mathrm{~W}$ ratios, except one data of $+5.1 \mathrm{ppm}$, which belongs to a massive flow. Sample LH-02 showing parallel spinifex texture has the lowest $\mu^{182} \mathrm{~W}$ ratio down to $-8.1 \mathrm{ppm}$, and the mean for all six data points is $-2.8 \pm 3.1 \mathrm{ppm}$ (1SD). Similarly, sample LH-01 displaying chevron spinifex texture has slightly negative values varying from -7.3 to zero ppm, with an average $\mu^{182} \mathrm{~W}$ of $-3.8 \pm 2.8 \mathrm{ppm}(1 \mathrm{SD}, \mathrm{n}=6)$. The $\mu^{182} \mathrm{~W}$ values of Sample LH-03 vary in between -6.5 and $+5.1 \mathrm{ppm}$ and average at -1.7 $\pm 4.2 \mathrm{ppm}(1 \mathrm{SD}, \mathrm{n}=6)$. It's worth noting that large variability of $\mu^{182} \mathrm{~W}$ within sample scales is attributed to the use of a small sample load $(\sim 0.5$ gram $)$ for digestion and the inhomogeneity of $\mathrm{W}$ distribution in the rocks is allowed to be detected. All 18 analyses exhibit an average $\mu^{182} \mathrm{~W}$ of -2.7 $\pm 3.4 \mathrm{ppm}$ (1SD), unresolved from the modern mantle-like ${ }^{182} \mathrm{~W}$ isotope signatures within analytical uncertainties $( \pm 5$ ppm, 1SD).

Detailed investigations on the petrology, geochemistry and metamorphism suggest that the Taishan Komatiites are free from significant hydrothermal alteration, crustal contamination and metamorphic disturbance. Hence, we regard the lack of ${ }^{182} \mathrm{~W}$ excess as an intrinsic feature of the $\sim 2.7 \mathrm{Ga}$ Komatiites in the Taishan region. Notably, the contrasting $\mu^{182} \mathrm{~W}$ values in between the Taishan and Boston Creek komatiites ${ }^{[1]}$ suggest a heterogeneity in $\mu^{182} \mathrm{~W}$ in the $\sim 2.7$ Ga mantle. On the other hand, it's likely that the $\mu^{182} \mathrm{~W}$ of the Earth mantle has started to decrease to zero at $\sim 2.78$ to $2.65 \mathrm{Ga}$, complying with the $\sim 3.6-2.5 \mathrm{Ga}$ silicate Earth W isotope transition model ${ }^{[2]}$ and suggesting a moderate mixing efficiency for Earth mantle convection.

[1] Puchtel et al (2018) GCA 228, 1-26, [2] Mei et al (2019) GCA. 